\title{
Study on Standardized Work Suitable for Smaller
}

\section{Enterprises}

\author{
Kenichi Iida ${ }^{1}$, Masahiro Shibuya ${ }^{2}$ and Koki Mikami ${ }^{3}$ \\ 1. Industrial Research Institute, Hokkaido Research Organization, Sapporo 060-0819, Japan \\ 2. Faculty of System Design, Tokyo Metropolitan University, Tokyo 191-0065, Japan \\ 3. Faculty of Future Design, Hokkaido University of Science, Sapporo 006-8585, Japan
}

\begin{abstract}
Many smaller manufacturers utilize production systems such as "individual production" and the "production of many models in small quantities." In the processes for the "production of many models in small quantities” by multi-skilled workers, a manufacturer cannot make good use of the management method with standardized work tables used by large enterprises. Thus, it is necessary to develop ways to find standardized work that is suitable for smaller enterprises. Therefore, we investigated two kinds of factories that utilized flexible manufacturing procedures for the "production of many models in small quantities," and considered their work instructions, work contents, changeover methods, workers' abilities, etc. One of the compared processes was a case where there was defined standardized work, which was not observed. In the other, a QA (quality assurance) network was created to guarantee the quality. Based on the investigation results, we formulated improvement plans, had the supervisors review them, and clarified the characteristics of their problems. The results revealed areas where much attention was required to find standardized work for such processes. In addition, we made it possible to support the specification of difficult tasks and the renewal of standardized work by extending a standardized work table for the entry of workers' actions. This paper reports a method to define and make good use of standardized work tables and standardized work combination tables, i.e., a way to find and use standardized work based on the results of the previously mentioned factory investigation.
\end{abstract}

Key words: Manufacturing process management, standardization, standard work, PDCA (plan-do-check-act), kaizen.

\section{Introduction}

In Japan, there have been rapid changes in the manufacturing industry’s environment. In particular, bitter competition with other Asian countries and an increase in overseas production by major makers have forced the smaller enterprises sustaining the domestic framework to take stern actions. Two methods to solve these problems are the "production of value-added products" and "production using smaller numbers of workers to produce numerous models with shorter delivery times." However, the former is difficult for smaller enterprises with limited funds. An even worse problem is their inability to defeat large enterprises without quickly developing new products. Therefore, it

Corresponding author: Masahiro Shibuya, associate professor, doctor of philosophy, research field: production and operations management. is important to find methods for solving the latter problem.

Production in the manufacturing industry requires an awareness of QCD (quality, cost, and delivery), and work management is important to promote QCD. The major automobile manufacturers have established methods for standardized work tables (process capacity sheets, standardized work tables, and standardized work combination tables), 5S' (Sort, Set In Order, Shine, Standardize, Sustain), visualization, etc., and have used them in the installation of equipment in their production lines, work streamlining, and improvement, which have actualized highly effective production. Standardized work is used in these methods. By eliminating experiential knowledge and instincts and making workers perform standardized work, workers with little experience like seasonal workers can work effectively. 
On the other hand, smaller enterprises have many different factors affecting their production, such as heavy fluctuations in production and a small number of workers. Thus, they cannot obtain a good introduction effect without considering the differences in their production patterns when they use the standardized work tables of major enterprises.

A textbook says that the standard work is the product of the technical standard and the process standard [1]. Smaller enterprises have various kinds of workers, including the elderly, part-time employees, and experienced workers, and many smaller enterprises manage without enough workers. If great emphasis is placed on efficiency while ignoring the workers at the worksite, it aggravates unemployment and undermines the entire industry. Kumashiro stated that it is always necessary in job design to grope for a work system that conforms to the specific characteristics of human beings [2]. Ilmarinen defined work ability as a worker's ability to accomplish his or her work, and developed the WAI (work ability index) in 1981 [3]. The WAI was developed to evaluate the work ability of the aged. A worker with a low WAI evaluation is expected to have a strong possibility of not being able to continue work in the near future, but it is difficult of use the WAI for job design. The work re-design [4-6] that we conducted suggested the necessity of adding an item for "workers" to the formula. In addition, we believe that considering various kinds of workers and environments when developing work standards, such as elderly workers and part-time female workers, as well as pursuing production efficiency and cost reduction, will assist in supporting smaller manufacturers.

We investigated the production lines for small quantities of numerous models with production-order latitude, and reported the problems concerning the setting and usage of standardized work from the viewpoint of workers in this paper.

\section{Aim and Method}

We propose a "work re-design support system" to provide a work management tool that is suitable for the production of numerous models in small quantities. Our aim is a support system that systematically supports the improvement of work methods, workers' processes, and so on [7]. We believe that it is possible to establish a friendly work management method for smaller manufacturers by finding a standardized-work method suitable for various production modes using direct observation. This is because the entire work process should be immediately improved by paying attention to various kinds of workers and tasks.

Therefore, it was decided to classify the issues into two groups and then solve these.

Issue 1: Support the standardization of work processes and enable premeditated production.

Issue 2: Enable work standardization that takes the age or gender of workers into consideration.

The purpose of this study was to solve these issues, and it was necessary to visualize everything related to production.

This paper principally discusses the problems and how to solve them based on the results of the factory investigation. The procedure of the research was as follows:

(1) Developing a concept model;

(2) Factory investigation (two kinds);

(3) Presentation of the investigation results and improvement plans to the worksite supervisors;

(4) Discussion;

(5) Modification of the concept model.

\section{Results}

\subsection{Concept Model}

Fig. 1 shows the concept model of the work re-design support system. This figure shows the problems found in our previous investigation. These problems show the starting point of work management where standardized work should be revised and fostered, which indicates the importance of the mechanism for seamlessly supporting improvement activities. To verify the model, we investigated two factories. One was a case where 


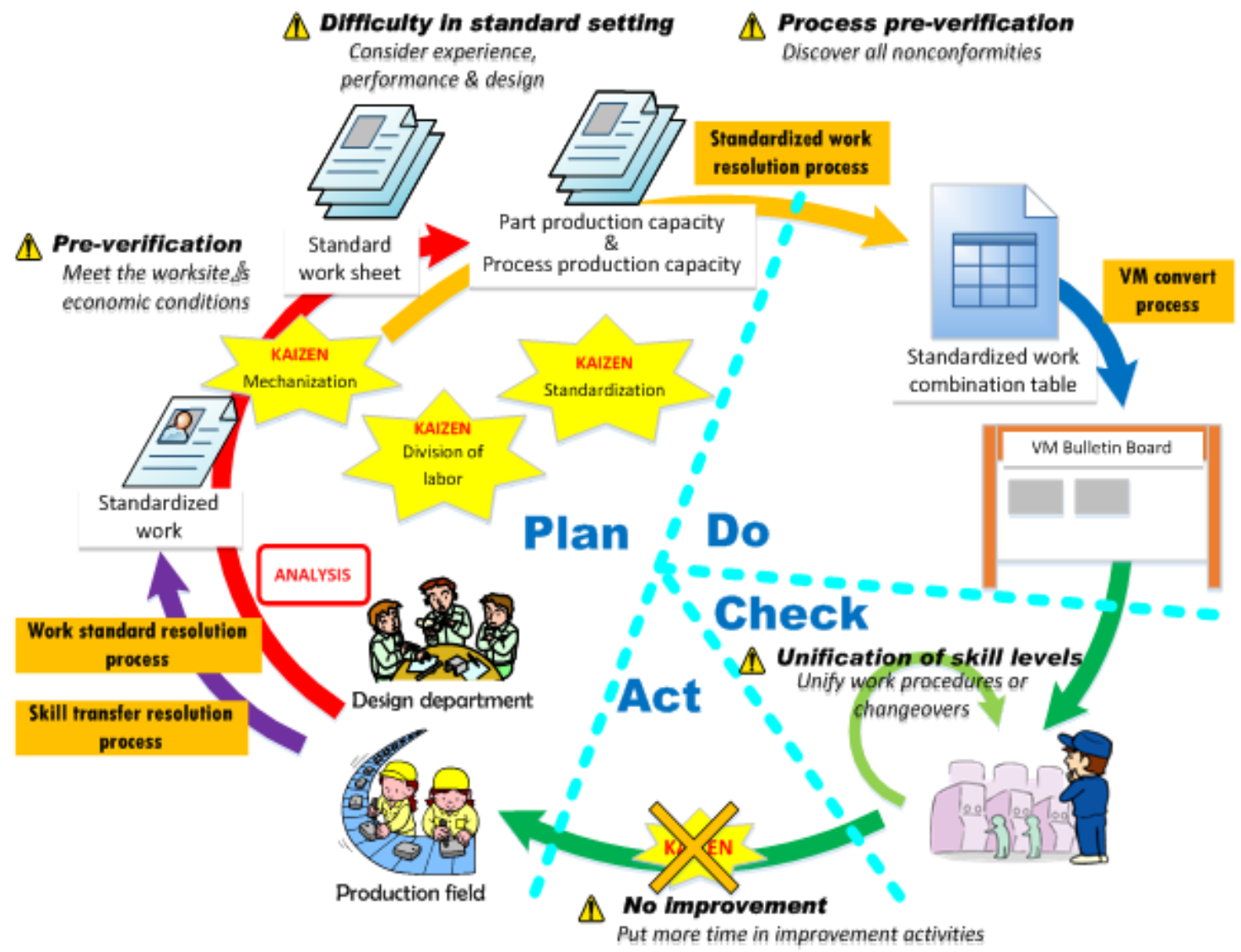

Fig. 1 The concept model of the work re-design support system.

the standard was decided according to the processing machines. The other was a case where the standard was decided by the use of a QA (quality assurance) network. The problems found through the investigation and how to solve them are examined here.

\subsection{Factory Investigation}

There have been very few studies or reports that have clarified procedures or methods to standardize work, such as by determining "in what order work should be conducted for the ideal" and "how to gather and analyze necessary information.”

In order to find a method for standardized work for the work re-design support system, we investigated smaller metal processing enterprises, where much of the work is labor-intensive and dependent on manual work, as well as being complicated and hard to manage.
3.2.1 Case Where Standard Was Decided According to Processing Machines

This enterprise was a mid-scale manufacturer with 76 employees making farm equipment and heating devices. Our target was part of the sheet-metal processing line used to manufacture parts for heating stoves. At this factory, the worksite supervisor made standardized work combination tables and gave instructions to his workers.

Fig. 2 shows the layout of the target lines. Two workers in Line A conducted 18 processes, and two in Line B conducted 10 processes to make our target parts. The numbers in the figure show the process numbers, which show that the manual work and automatic processing were mixed together. In the lines, four workers performed their work using the one-flow method, which required $50 \mathrm{~s}$. There was a tendency for the hand-passing to increase in the process because each worker's work time was different. 


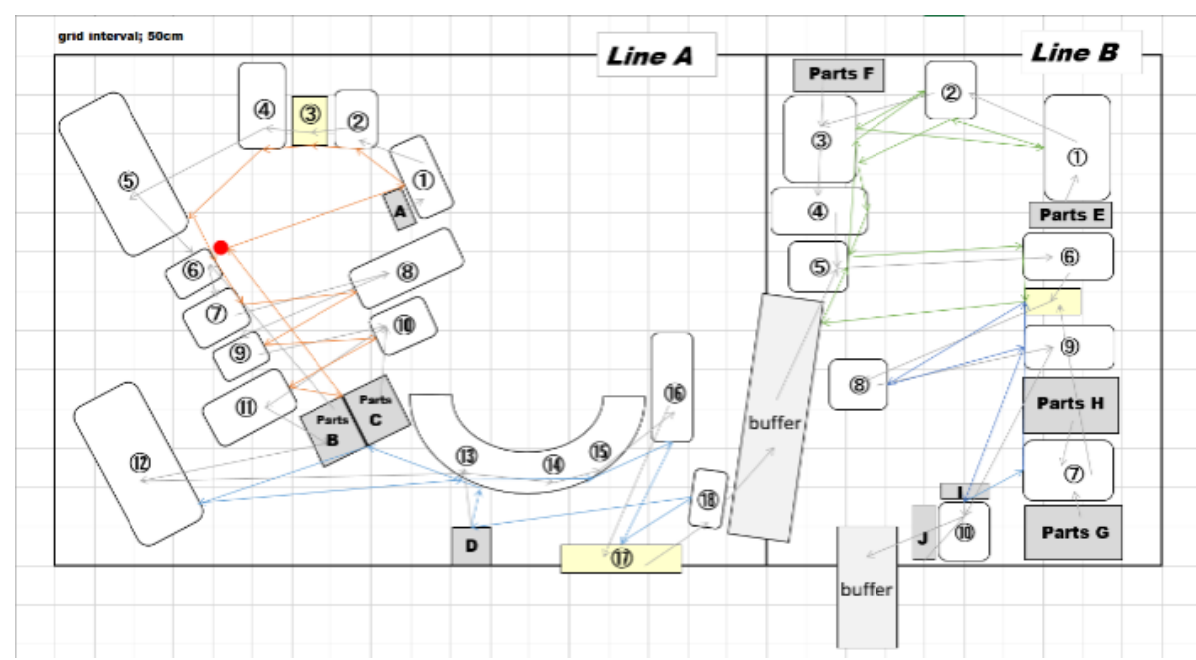

Fig. 2 The layout of the target line.

\begin{tabular}{|c|c|c|c|c|c|c|c|c|c|c|c|c|}
\hline 4 & A & B & C & D & $E$ & $\mathrm{~F}$ & $G$ & $\mathrm{H}$ & 1 & J & $\mathrm{N}$ & 0 \\
\hline 1 & \multirow{2}{*}{ Process } & \multirow{2}{*}{ A region } & \multirow{2}{*}{ Order } & \multirow{2}{*}{ Content } & \multirow{2}{*}{ Occurrences } & \multirow{2}{*}{$\begin{array}{c}\text { Target } \\
\text { components }\end{array}$} & \multicolumn{4}{|c|}{ A manufacturing process } & \multirow{2}{*}{$\begin{array}{l}\text { Quality } \\
\text { level }\end{array}$} & \multirow{2}{*}{$\begin{array}{c}\text { Total } \\
\text { evaluation }\end{array}$} \\
\hline 2 & & & & & & & $\begin{array}{c}\text { Parts } \\
\text { accepted }\end{array}$ & Parts & $\begin{array}{c}\text { Parts- } \\
\text { assemble }\end{array}$ & Inspectio & & \\
\hline 3 & \multirow{4}{*}{ Parts } & \multirow{4}{*}{ Upper Unit } & 1 & & expectation & diaphragm & & (1) & 【1】 & & (1) & A \\
\hline 4 & & & 2 & & expectation & diaphragm & & (3) & 【1】 & & (3) & A \\
\hline 5 & & & 3 & & & damper & (3) & & & & (4) & D \\
\hline 6 & & & 4 & & & damper & & & & & & $\mathrm{C}$ \\
\hline 7 & \multirow{2}{*}{ Parts } & \multirow{2}{*}{$\begin{array}{l}\text { Inner } \\
\text { Unit01 }\end{array}$} & 1 & & & diaphragm & & & 【3】 & & (3) & A \\
\hline 8 & & & 2 & & & diaphragm & & & 【4】 & & (3) & $A$ \\
\hline 9 & \multirow{2}{*}{ Parts } & \multirow{2}{*}{$\begin{array}{l}\text { Inner } \\
\text { Unit02 }\end{array}$} & 1 & & expectation & seal & & & & & & $\mathrm{B}$ \\
\hline 10 & & & 2 & & expectation & seal & & & & & (3) & $\mathrm{A}$ \\
\hline 11 & Parts & Left Unit & 1 & & expectation & diaphragm & & & & & & $\mathrm{B}$ \\
\hline 12 & \multirow{3}{*}{ Parts } & \multirow{3}{*}{ Front Unit } & 1 & & expectation & diaphragm & & (1) & 【1】 & & (1) & $A$ \\
\hline 13 & & & 2 & & & diaphragm & & & & 【1】 & (2) & A \\
\hline 14 & & & 3 & & & diaphragm & & & & 【1】 & (2) & A \\
\hline
\end{tabular}

Fig. 3 The QA network (transcribed in part).

Based on their own judgment, some workers performed their next process if possible when another worker's work was stagnating or blades were exchanged. Some workers repeated part of the cycle considering the situation. In the changeover work, some workers consulted each other, checking the plan for the production method or the arrangement of processing machines, about which their supervisor had not given any instructions. Soon after the production of parts was finished, the changeover started for the next production. Thus, they did not find problems or implement improvements.

3.2.2 Case Where Standard Was Decided by Use of QA Network

This enterprise was a mid-scale manufacturer with 82 employees making electric wires and panel heaters.
Our target was the assembly line for electric regenerators. At this factory, work instruction sheets were made in the design department using a QA network, and passed to workers. A QA network is a process-creation method that disables the flow of defective parts to the next stage by predicting their occurrence at each manufacturing process. Fig. 3 shows the QA network used in this case. The manufacture of electric panel heaters was conducted by workers who understood the work instructions in the cell production system. The standard assembly time was $1 \mathrm{~h}$. At the time of our investigation, two workers conducted this task in parallel, and the assembly time of the more skilled worker was 10 min shorter than the standard assembly time. The work was conducted after three sets of materials were prepared beforehand. 
Based on their own judgment, some workers assembled more than one part temporarily or changed the order of assembly. This means that the workers did not have enough training, but could make the assembly time much shorter based on their abilities.

\subsubsection{Investigation Results in Common}

The skilled workers completed their task, understanding the instructions for the standard task and adding their own improvements. The supervisors wrote a "Report on the amount of work done by their workers" and conducted a "Sampling inspection" in the "Check" part of the PDCA (plan-do-check-act) cycle. They did not do anything in the "Action" part.

The worksites were analyzed from different angles, and the following nine problems were pointed out:

(1) How to handle the failure of a processing machine was unclear;

(2) Hand-passing in the process caused delay;

(3) Conversation among workers;

(4) Actions based on quick judgment from experience;

(5) Some work with no one responsible for its process;

(6) Work outside the area;

(7) How to resupply parts;

(8) Blade-exchange fell on one worker;

(9) Work order and layout.

Items (1) (7) were not in the standardized work table, but the others were there.

After the investigation, we reported the investigation results and improvement plans to the supervisors, and verified the items pointed out.

\section{Discussion and Measures}

The following two points were examined based on the results of the factory investigation.

Comparison of the field research and standardized work tables:

- Workers' actions;

- Work procedure;

- Changeover;
Re-examination of the finding process for standardized work:

- Criteria for problem discovery;

- Discovery of workers' abilities;

- Items necessary for standardized work;

- Management by use of performance lists.

\subsection{Procedure}

It is necessary to repeat a fixed work procedure in standard work. However, at these worksites, in a case where a delay was caused by a worker, other workers made a judgment about their circumstances and conducted another practicable task instead of just waiting. In the production of many models in small quantities, the products and their numbers vary according to the orders received. To cope with that, training was conducted at these worksites to foster multi-skilled workers who could flexibly deal with various kinds of conditions. Although the work procedure is important, it is necessary to develop a flexible system that makes it possible to flexibly cope with various kinds of problems.

The major manufacturers provide detailed instructions about work methods, the arrangement of machines/equipment, etc. However, the workers at the two places investigated consulted each other and decided on the manufacturing method and arrangement for the processing machines. It is thought that the abilities of skilled workers will lead to good operations. Our investigation made it clear that the abilities of skilled workers (experience, intuition, etc.) could contribute to good performance in some cases, while they did not in other cases.

In handing down skills or technical knowledge, the supervisor must judge whether the skilled workers' abilities are beneficial and should be handed down to younger workers.

\subsection{Ability to Make Best Use of "Check" \& "Action"}

Time research is conducted to promote efficiency and set a standard time. The standard time can be 
defined as "the time for a skilled worker with a good aptitude in his work to accomplish his work with the necessary allowance at the right pace under a fixed work condition.” The standard time consists of three parts: the main work time, work time needed for preparation and set up, and allowance time. The factors used to determine the standard time include the workers' skill and work pace. Thus, it is necessary to base the standard time on the data for the basic time values previously obtained from the work contents, which requires much skill.

Therefore, we found the standard time using a direct time measurement method, which used data recorded with a video tape recorder for the work analysis. The assembly time was much shorter than that of the standard work. This was because skilled workers conducted the assembly work, devising the work method. In the factories, each worker devised an assembly procedure for the work given by his supervisor, but the know-how was not shared among workers. The supervisor did not care about it because the assembly time and quality fulfilled the criteria. The supervisor at the worksite defines the standard work. He establishes the best standard and instructs his workers. It is necessary to constantly observe the production site, and keep improving and revising the fixed standards, not leaving them as they are. In this case, the assembly time would have been $10 \%$ shorter if the fastest worker's procedure had been made known to all the workers as the standard.

\subsection{A Solution}

Based on a standard work table in common use, we developed an extended-type standard work table as a simple solution because it was suggested that observation during manufacturing was important. Fig. 4 shows Worker A1's standardized work table. The table contains incidental work time such as for the "resupply of parts" and "work for the replacement of buffers," along with "delay," which are not seen in ordinary work tables. These were seen in the actions

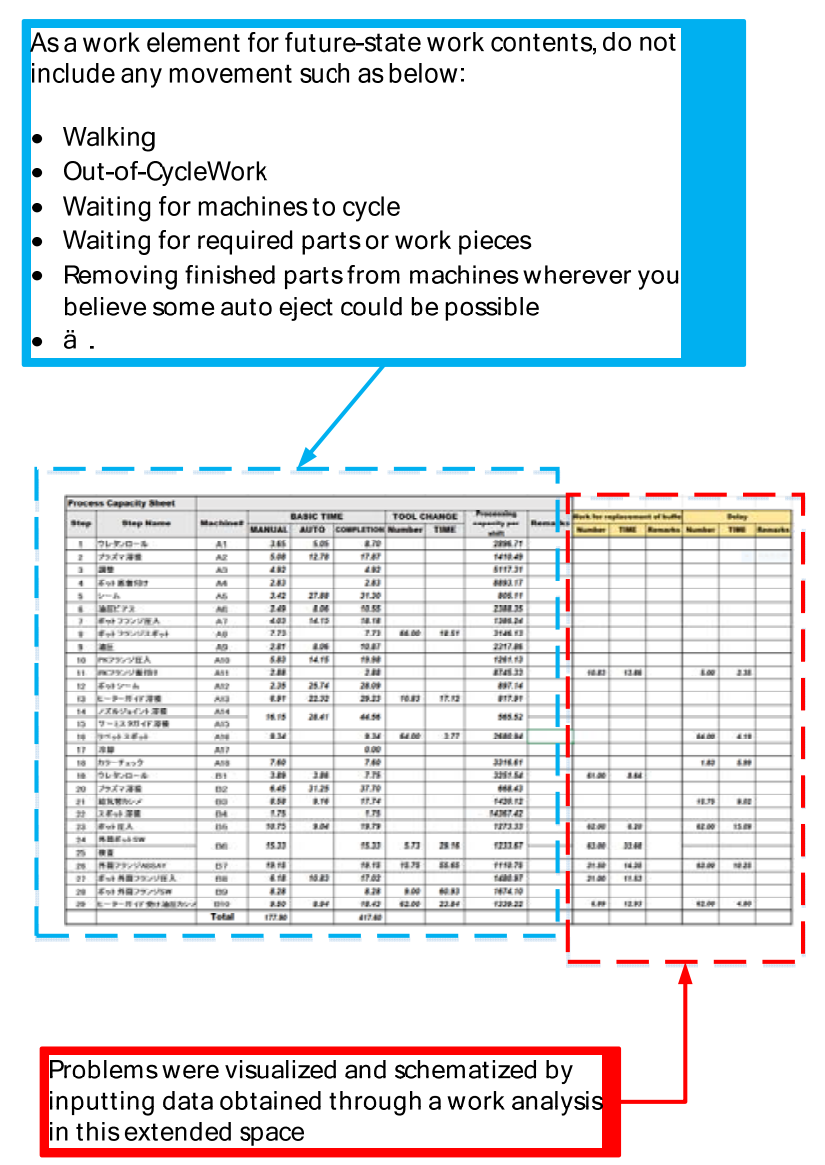

Fig. 4 The investigation results.

of all the workers. Moreover, there were some actions that were impossible to enter. One instance was when "One worker repeated a certain part of the work." This is usually treated as "management allowance." However, considering the ratio to one cycle or the number manufactured, the value was a non-negligible one, and we decided to make an entry by extending the right side of the process capacity sheet.

Problems were visualized and schematized by inputting data obtained through a work analysis in this extended space, which could lead to more improvement activities and one more use of the PDCA cycle. At worksites producing many models in small quantities, the supervisors are too busy with their daily work to revise the fixed standards. In many cases, the "Action" part of the PDCA cycle is not practiced, and improvement activities are not conducted. At the worksites producing many models 
in small quantities where we performed the fact-finding surveys, the "Check" and "Action" parts were neglected.

\section{Conclusions}

It was made clear that in the production processes for many models in small quantities by multi-skilled workers, much attention should be paid to the following points to find standardized work.

- You must not eliminate actions that are not included in standardized work, because workers perform various kinds of tasks.

- You can find skilled workers' abilities such as experience and intuition by analyzing their actions that are not included in the items of standard work.

- You can find problems by setting criteria using one cycle that runs well in the 1st investigation, and then comparing them with the results obtained in the 2nd investigation, by element.

- The problems found here lead to a determination of a bottleneck process, and make it possible to clarify improvement priorities.

This paper proposed a support system for revising standardized work. Using this system, it is only necessary to record actions that differ from the fixed work procedure in the extended standardized work table after directly observing the worksite. The decision about whether or not to include the content in the revised standard is left to the determination of the supervisor, but it was suggested that this could be a tool for continuous improvement activities because workers are made to record what they have done during the day.

Developing a dynamic standardized work table that is suitable for various types of industries can actualize a useful tool for solving the following two problems:

(1) Reducing workers' workload imbalance at a production site such as a cell production line with multiple workers;

(2) Finding bottleneck processes and clarifying improvement priorities.

In determining a standard for smaller enterprises, it is important to extend the formula in the textbook [1] as follows:

Standards $=$ Technical standards $\times$ Process standards $\times$ Workers' standards.

\section{References}

[1] Productivity Press Development Team. 2002. Standard Work for the Shopfloor (The Shopfloor Series). New York: CRC Press, 14-33.

[2] Kumashiro, M. 2002. "Japanese Initiatives on Aging and Work: An Occupational Ergonomics Approach to Solving this Complex Problem.” In Aging and Work. London: Taylor \& Francis, 1-8.

[3] Ilmarinen, J. 2002. "Promotion of Work Ability during Aging. Aging and Work.” In Aging and Work. London: Taylor \& Francis, 21-36.

[4] Mikami, K., Shibuya, M., Sasaki, G., Funada, N., Hasegawa, T., and Kumashiro, M. 1998. "A Supporting System for Work Improvement to Create a High-Productivity Work Place-A System for Evaluation the Burden of Work Postures and Virtual Simulation.” In Global Ergonomics, edited by Scott, P. A., Charteris, J., and Bridger, R. S. Amesterdam: Elsevier, 497-500.

[5] Mikami, K., Shibuya, M., Iida, K., Hatazawa, K., and Kumashiro, M. 2003. “A Study of Improvement in the Production Line for Dairying Implements Aiming for the Fusion of Productivity and Humanity.”Asian Journal of Ergonomics 4 (1): 37-47.

[6] Shibuya, M., Mikami, K., Iida, K., Hatazawa, K., and Kumashiro, M. 2007. "A Study of Work Management for Female Workers at a Food Processing Company." Presented at the Eighth Pan-Pacific Conference on Occupational Ergonomics, Bangkok, Thailand.

[7] Shibuya, M., Iida, K., and Mikami, K. 2013. "A Study for Automaking of Standardized Work Combination Forms Suited for Smaller Enterprises.” Presented at the 22nd International Conference on Production Research (ICPR22), Brazil. 